\title{
Understanding Amsterdam Airport Schiphol through controversies:
} $A$ response to van Buuren, Boons and Teisman

\author{
Bart de Jong* \& Luuk Boelens**
}

\begin{abstract}
Due to increasing multi-actor networked world, the decision making process about complex governance systems, such as the Amsterdam Airport Schiphol (AAS), is experienced incremental and highly indecisive. Often, in these cases, collaborative arrangements are created as aiding vehicles to tackle these complex problems. Two of these arrangements have been recently analyzed in "Systems Research and Behavioral Science", with regard to AAS. In reference to these analyses, one concluded that the self-organizing capacity of those collaborative arrangements, intertwined with the complex system characteristics of the involved governance system, would improve the impact of the problem solving capacity with regard to complex issues. In this article we will argue that these analyses are far from complete. Instead, this contribution argues that they are only minor parts of the solution, even resulting in misguiding conclusions. On the basis of a more profound actor-network analyses, we will show that one of the most appreciated of those collaborative arrangements - the Alders-Table - is in fact hardly successful at all, nor reducing or resolving the complexity of the governance decision. Sooner these arrangements have condensed it into larger, newer and sharper controversies. From here we suggest that - instead of complicating the problem towards more complexity, hoping that this route would avoid path dependencies and bring new solutions - there is rather a need to clear 'the disposition of complexity' profoundly. Instead of linking complexity to its specific governance settings, we would sooner need a (re)focus on more concrete associative opportunities, and co-evolution beyond political agenda's and/or plans.
\end{abstract}

Keywords: Actor-Network theory, urban planning, collaborative decision-making, governance, airport planning

* Bart de Jong is.....

** Luuk Boelens is full professor of Spatial Planning at the Centre for Mobility and Spatial Planning, and Geography Department at Ghent University, guest professor of Regional Planning and Urban Design at the Department of Human Geography and Urban and Regional Planning at Utrecht University and managing director of the Dutch planning consultancy firm Urban Unlimited (Luuk.Boelens@skynet.be). 


\section{Introduction}

As a result of on-going 'glocalized', networked and empowered societies, the complexity of political decisions has grown massively (Boelens 2009, Teisman et al. 2009). There is a multiplicity of stakes associated with specific issues while, at the same time, there are often disagreements about values, norms, objectives, research, information and knowledge; leading to complex and unstructured problems (Hisschemöller and Hoppe 2001). This is also the case with regard to complex governance systems such as major airport hubs. Especially when new plans are made to expend those hubs, these complex controversies emerge to surface. In these cases a multiplicity of stakes and perceptions show up, within a kind of multi-actor and multi-scalar system of divergent, but interdependent interests. Moreover the decision-making process with regard to these airport hubs leads to disagreements, ambiguities and uncertainties concerning facts and values. As a result science and politics become highly mutually intertwined. The various and ongoing policy decisions with regard to for instance Amsterdam Airport Schiphol (AAS) are exemplary in that respect. AAS has evolved from a rather straightforward object (an airfield strip or gateway to the world) into a highly multi-interpretable, interrelated and therefore complex system, in which neither science, nor politics, or the involved businesses and citizens have the final say. It results in a decision-making process perceived as incremental and highly indecisive (De Jong, 2012). To deal with this indecisiveness and muddling through, consultative bodies are created, which would help to stimulate a broader support and more resilient solutions. These consultative bodies regularly consist of involved actors, which all have their own meanings and values that are fixed and securely anchored in their own contexts and interests, as in the histories of their surroundings as well. This leads to situations in which planners, architects, engineers, technology users, or other groups are constrained by fixed ways of thinking and interacting (Hommels, 2011). As a result, and instead of real resilience, often political deadlocks emerge.

In their contribution to Systems Research and Behavioral Science (Syst.Res. 29, 116-130, 2012), Van Buuren et al. assess how to overcome these deadlocks. They stress that the literature on collaborative problem solving often underestimates and neglects the characteristics of the governance system, in which the attempts of that kind of collaborative problem solving is organised. They argue that to organize a successful collaborative arrangement, the complex system characteristics of the governance system, in which such an arrangement is applied, needs to be taken into account (Van Buuren et al., 2012). As such they analysed the so-called Alders Table as a collaborative problem-solving effort concerning AAS. According to Van Buuren et al., the Alders Table would be deeply embedded in the complex airport governance systems, 
intertwined with the outside world, bringing the agendas of other subsystems together, and integrating them by creating an indivisible output, presided by a respected chairman.

Although the analyses rightly stresses the need to include the way in which problem solving is always reciprocally connected to its surroundings, we also want to criticise this assumption, as the point Van Buuren et al. make bites its own tail. Linking collaborative decision making to the complex governance system in which it occurs, is not sufficient in overcoming the political deadlocks with regard to the divergent, but mutually intertwined ambiguities of facts and values. On the contrary, looking at the Alders Table more profoundly, beyond its apparent outcomes, this table is far less successful as Van Buuren et al. want us to believe. We are convinced that this misguidance is the result of the fact that in their case study Van Buuren et al. seem to be more concerned with 'ready made policies', instead of 'politics in the making'. If they did focus on the latter, major and evolving controversies would become apparent within the final Alders advice, which are now covered by a hardly resilient 'cloak of mutual conformity'. Moreover Van Buuren et al. don't pay attention to the decisive agency of new and evolving technologies within the entangled networks of sociality and materiality, resulting in unprecedented, non-linear and fuzzy political problems. At least in retrospect, this is a major omission studying complex governance systems like airports, as precisely in and around airports these kinds of sociotechnical controversies occur time and again. Therefore politicians usually consider airport planning a headache portfolio (Boelens \& De Jong 2006).

To improve insights in complex governance systems, like major hub airports, and to improve the decision making process in this area, we will analyse and understand the Alders Table by shifting the focus from 'studying complexity' towards the study of 'the disposition of complexity'. We will try to understand the deadlocks mentioned above in a more explanatory and operational way. To that end we will use the Actor Network Theory (ANT), as it not only takes the mutually intertwined impact of facts and values, governance and governance system for granted, but is also even more focussed on (collaborative) politics in the making through sociotechnical controversies. Therefore we start the discussion by shortly describing this theoretical point of departure (section 2). From these insights we will come back to the Alders Table, showing how the final advice evolves around several controversies (section 3). In section 4 we will compare these insights with those of Van Buuren et al., and shed new light on the question if deadlocked situations can be tackled, only by organising collaborative processes within the context of complex governance systems. We will conclude with some recommendations how to improve the decision-making processes in these areas in a more resilient way. 


\section{Introducing the Actor-Network Theory}

According to ANT, it makes no longer sense to approach decision making as unambiguous, or as processes whereby socio-technological objects can be governed by clear-cut planning concepts and governance approaches. Present day society is far too multi-level and multi-actor networked, dynamic and non-linear to deal with its interests, ambitions and problems in a predefined manner. Instead, the strategy evolves reciprocally during the process. Moreover governance not only deals with the specific interests, ambitions and problems of the actors at hand, but also has become part of these problems and ambitions itself. Moreover in these processes there are no pre-given, unambiguous facts; facts and values have become highly intertwined. Or in other words: facts have become a matter of (mutual) concern. There can be acute struggle which facts should be taken into account or even what or how far they should account for.

These insights of ANT shed especially new light on decision and planning domains like major airport hubs. Because facts with regard to for instance noise nuisance, air pollution, the contribution to the regional economic welfare, added value, international competence etc. mostly prevail the discussion with regard to the expansions plans of these airports. ANT however stipulates that facts are far less unambiguous as experts or scientist want us to believe. While the discussions with regard to the future (expansion) plans of major airport hubs mostly focus on these so-called 'objective facts' (for instance with regard to noise or air pollution) or 'improved techniques to deal with them' (for instance with regard to hindrance removing or reducing measures), ANT claims that these facts and these techniques are part of the problem themselves. In this respect, and instead of focussing on the decision-making process or the governance system itself, one should focus on the series of socio-technical controversies, which proceed during planning and policy-making processes themselves in their quest for successful or mutual accepted solutions. Because, according to ANT, concerned actors do their best to render statements as either fact or fiction. Mapping and interpreting these kinds of statements, or better still the ongoing controversies around them, was initiated by Bruno Latour, Michael Callon, John Law and others. It is regarded a major contribution to the development of the ActorNetwork Theory (ANT). Especially Latour observed and interpreted social debate around controversies on techno-scientific issues. As such it is highly suitable for our case.

ANT enables readers to understand how actors construct 'realities' by forming networks of relations, or associations, on the basis of controversies. It starts from three notions. 
First, a priori definitions are obsolete. According to ANT we cannot define 'definitions', 'methods', 'domains' or 'questions' and 'problems' beforehand (Latour, 2005). Instead and according to ANT, those 'definitions', 'methods', 'problems' etc. are the result of mutual commitment, or in other words: actor-networks. Instead of researching already established connections, ANT therefore follows actors that construct their set of associations. Only when associations have been established and accepted, social explanations or definitions can be convincing.

The second notion is 'the principle of symmetry'. ANT abandons the traditional sociological separation of the human and material world; culture and nature. Non-humans (or in our case: planes, flight-tracks, noise-nuisance recording systems etc.) are as important as humans (or in our case: the CEO of the Airport, the Directors of the Airlines, the involved businessmen, the citizens, politicians and the like). To stipulate this, ANT speaks here about actants, instead of actors. As such an actant is any element that bends space around itself and makes other actants or elements dependent upon it (Callon and Latour, 1981). Although ANT theorists do not deny the difference between human and non-human actors, they claim that an explanation of the mutual emergence of both has to be studied symmetrically, and at the same time in real practices.

ANT thirds notion is (partly in concordance with this), that in principal and in the beginning all actors are equal: if actants are larger, we should study how this comes about - how, in other words, size, power, or organization are generated (Law, 1992). Power is not yet there but it is composed as a result of collective action, whereby that action is attributed to just or mainly one actant (Latour, 1986). As such ANT theorists claim that power is a result and not a cause. So, and in our case, one could not define beforehand who could or should decide about the plans or the future developments of major airport hubs. The power to direct is the result of the global/local actornetworking between the most involved human and non-human stake- and shareholders in reference to those plans.

As such, ANT seems to be a suitable theory to come to a clear understanding of the emerging deadlocks around hub airport policies; imbued as they are with social and technical uncertainties, leading to an incremental and indecisive decision-making process. Moreover, ANT can help finding solutions to bridge the gap between existing and normatively valued situations of airport-hubs, like Schiphol.

First, ANT provides a radical account of space and time, stating that space and time are not underlying autonomous structures but rather multiple enactments and assemblages. Next, ANT is not interested in the epistemological status of scientific knowledge and delegative politics, but focuses on the production of such knowledge and politics as an ontological achievement. Last 
but not least, ANT grasps the multiplicity of processes of becoming, and affixes socio-technical networks, hybrid collectives and alternative topologies (Farías, 2011). These three central notions show how boundaries between science and the social, values and facts, technologies and politics, humans and objects etc., are blurred. ANT shows how Schiphol is not socially constructed, but assembled into being, in networks of materialities, bodies, technologies, objects, natures and humans (Mol, 2002). There are multiple enactments of Schiphol and the major challenge is to understand how these multiple geneses are articulated, concealed, exposed and made present or absent. Therefore ANT claims that the focus should shift from 'ready made politics' towards policy in the making and especially the disposition of its complexity. ${ }^{1}$

As such actor-network theorists try to investigate why and how associations between actors and entities come into existence. In this respect ANT uses the notion of translation (Callon 1986), which is in fact a non-linear process used by a focal (or initiating) actant to translate and enroll others to identify with the network, either consensually or coercively, and eventually come up with a communal strategy. Callon (1986) distinguishes here four phases problematization, interessement, enrollment and mobilization of allies. But the most important question behind this process is [h] ow can men act 'like one man'? (Callon and Latour, 1981). Therefore and in concordance with this Latour (2004) introduced the notion of the collective. This notion starts from a controversy and shows how we must follow this controversy in order to know which association eventually emerges. Even more, it could claim its potential power and/or resilience. Because, the more actors and entities assembled, the greater the influence of the association. Moreover an association becomes political, when innovations that drastically influence the prevailing practice, present themselves in and are accepted by the public. In this sense also 'the public' becomes rearranged, and possibly new associations between actans and issues come into existence. Latour believes that this sort of change in associations should be seen as a form of politics, which consists of creating new resilient associations, and/or the institutionalisation of those propositions into one firm association.

In this respect the notion of the collective and the process of translation provide generally deeper and more detailed answers, than a mere analysis of governance systems, issues, stakeholders and their divergent perceptions on norms and values. Therefore we will use this ANT toolbox to show how Schiphol, and in this case especially its consultative body of the

\footnotetext{
${ }^{1}$ And of course, that refers also to various other subjects or socio-technical domains (Mol 2002, Latour 2004, Marres 2005, Dijstelbloem 2007, Bender and Farías, 2011). However, the intertwinement of facts and values, the apparent disagreement and uncertainty about evolving technologies, and the blurred relations between science and politics, make the Hub file an extraordinary case, one that is extremely suited to an ANT approach.
} 
'Alders Table', is assembled into various networks of materialities, bodies, technologies, objects, natures and humans. Important to mention here are immutable mobiles: they must be seen as the 'transportation' of information (hence mobile) without the possibility of alteration (hence immutable). Maps, charts, reports etc. are prime examples of 'immutable mobiles', as they can be produced on a mass scale. These can be used to bring about new scientific knowledge and new cognitive powers, but they also lead to asymmetrical power relations between actors and entities involved. Therefore ANT also distinguishes between mediators (those that organize the associations or networks) and intermediaries (those that are organized within networks). And as such we can ask ourselves in this case, did the Alders Table - so much 'glorified' by Van Buuren et al. ,- serve as a 'mediator' or did it serve as a 'intermediary'. That makes the difference between the Alders Table just serving as an aiding, collaborative vehicle, or as a kind of 'Machiavellian' suppressor of meanings or real associations. To answer that question and to gain more in-depth understanding of the complex decision-making process with regard to airport hubs in general and AAS specifically, we executed a qualitative research method to analyze the Alders Table through investigating why and how actants influence and were being influenced by its progress. The three - extensively used - methodologies to gather, organize, validate and analyze the data were: analysis of documents and materials, observational techniques and open interviews. The research was conducted between 2006 and $2012 .^{2}$ We will show that during the formulation of a short-term and mid-term advice with regard to the future development opportunities of Schiphol, the Alders Table was confronted time and again with (socio technical) controversies, challenging the prevailing practice of as well Schiphol, as the Alders Table itself. As such the Alders Table did not so much get to a kind of collaborative problem solving in a complex governance system (as Van Buuren et al. wants us to believe). The Alders Table eventually only served and became a condensed multiplier for new and various controversies.

\section{Introducing Amsterdam Airport Schiphol and the Alders Table}

Amsterdam Airport Schiphol is the fourth airport in Europe in terms of passengers and air transport movements, and the third European airport when it comes to freight. The traditionally strong relationship between Schiphol Group (the limited liability company that owns the airport) and Royal Dutch Airlines KLM, which resulted in an extensive network of destinations, made sure that the airport could prosper despite a relatively small catchment area. Nevertheless, since its inauguration in 1916 the development of Schiphol has always been subject of discussion concerning planning and policy-making. Previously discussions were only

\footnotetext{
${ }^{2}$ For an extensive analysis see de Jong (2012).
} 
focused on the technical question how the airport should expand. Due to the evolving social and economic questions with regard to the jet engine, from the sixties onwards this discussion changed more and more to if the airport could or should expand. By the beginning of the 1990s after the global deregulation in the aviation industry - the national government introduced a scheme to secure future economic growth by expanding its hub-status and avoid ecological deterioration: the so-called dual objective policy. Since then, numerous collaborative bodies were installed to deal with the intricate task to balance economic growth and ecological sustainability. The Alders Table, founded in 2006, is only the latest example in this sense. This consultative body consisted of various involved public, civic and business representatives ${ }^{3}$ and was chaired by the former Minister and socio-democrat Hans Alders (hence Alders Table). While politicians and their civil servants were unable to solve the Gordian knot of Schiphol, it was asked by Parliament to formulate a political advice concerning the possibilities to utilize the environmental quality of the airport in a more sustainable and social way and at the same time secure future logistic capacity and economic developments. In October 2008 the Alders advice was presented to the responsible Minister, who spoke of a historical achievement. While never before so many different actors around Schiphol presented a so-called 'unanimous' agreement. The outcomes of the negotiations were therefore widely perceived to be a success story. However, reality - as the analysis below will describe - proves to be different.

\section{Mapping controversies}

\section{Controversy 1: The inhabitant's alternative}

Although the Alders Table was the next in row, for the first time ever, inhabitants were a formal part of a collaborative body concerning Schiphol. Dutch Parliament had demanded that the local residents would become part of the Alders table, as they expected the Alders Table to fail otherwise. The Dutch administration agreed and the citizens got their seat at the Alders table. However already at the second deliberation of the Alders Table in January 2007, they presented a citizens' alternative for the Environmental Impact Assessment (EIA), made by Schiphol and the Air Traffic Control Department of the Netherlands (LVNL). As the citizens were convinced that the EIA merely aimed to enhance capacity, while hollowing out legal protection against noise pollution even further. The citizens distinguished four points in their alternative:

1. They pleaded for a maximum capacity of 500,000 air transport movements at Schiphol and the relocation of 100,000 air transport movements such as cargo and low-cost carriers. At

\footnotetext{
${ }^{3}$ The Alders Table consisted of representatives of Schiphol Group, KLM, Air Traffic Control the Netherlands (LVNL), the former Ministry of Spatial Planning, Housing and the Environment (VROM), the former Ministry of Transport, Public Works and Water Management (V\&W), ${ }^{3}$ the municipalities of Amsterdam, Amstelveen, Uitgeest, Haarlemmermeer and the Province of NoordHolland, organized in the Managerial Directing Group Schiphol (BRS), and local residents organized in the Regional Schiphol Airport Consultation Committee (CROS) and the United Platforms of Residents against Airport Nuisance (VGP).
} 
the same time they pleaded for 'qualitative aviation growth': the focus should be on the hub operation of Air France/KLM.

2. Furthermore, they wanted a predominantly $2+1$ runway configuration. This meant that they opted for an alternative whereby the airport should use two take-off runways simultaneously with one landing strip, vice versa, depending on whether there is an inbound or outbound peak; because this operational strategy would reduce noise hindrance.

3. They wanted no adjustment to the prevailing limiting values of the existing noise enforcement points concerning aircraft hindrance.

4. And finally, they wanted no deterioration of the current quality of life in the surroundings of Schiphol in general. Sufficient compensatory measures would be needed to uphold the liveable conditions around Schiphol.

With these intentions the inhabitants looked strategically for and found a strong ally in KLM. Because the airline only underlined the hub operation of Air France/KLM at Schiphol and opted also in favour of a 2+1 runway configuration; as such the inhabitants and KLM met each other on these topics. Furthermore, the inhabitants realized that the Dutch Parliament explicitly requested Alders to include the inhabitants in the decision-making process. So backed up by the politicians they knew that the alternative proposed by them, had to be dealt with seriously by the experts at the Alders-Table; and the citizens decided not taking a passive, but an active stance. Subsequently the inhabitant's alternative was added to the environmental impact assessment; and the short-term Alders advice of June 2007 more or less consisted out of the items mentioned above.

\section{Controversy 2: 2+1 versus 2+2 deliberations}

In capacity terms, this short-term Alders advice stated that Schiphol could grow towards 480.000 flights in 2010. In order to realize this capacity, the criteria of the noise enforcement points needed to be changed or updated. However LVNL notified all Alders table parties that in order to deal with these updated flight numbers and to ensure safe in- and outbound peaks, air traffic - to a greater extent than in former years - would need to be handled on four runways at the same time, hence meaning a 2+2 runway operational strategy. That would mean that the short-term advice of the Alders table needed to be revised. Except LVNL, all parties concerned were not amused. At the following Alders Table the inhabitants did not show up, while the claim of LVNL would mean extra noise hindrance for the surrounding citizens. However the governments in BRS (see note 3) decided to leave as well, and KLM was furious. The KLM needed 80 take offs and 40 landings or vice versa per hour to maintain their hub-strategy. But the new operational proposal of LVNL only offered 60 take-offs and 60 landings per hour. 
Nonetheless, a month later, Alders persuaded the inhabitants to return to the Alders Table again. However the discussion concerning the $2+2$ runway configuration heated up, and trust and loyalty were questioned between the various stakeholders at the table. Thanks to his respected status of the former minister and his position as a commissioner of the queen, Alders forced the stakeholders to accept a dictated compromise, leaving the 2+2 runway configuration out. However, as a result LVNL's position at the Alders Table was weakened immensely, although they were the most prominent (and formally accredited) aviation regulator at the table.

\section{Controversy 3: Measurement system}

The ink of the new compromise was not dried up again, when a new controversy presented itself subsequently.. The immediate cause for this unforeseen shift was a recent conflict between the Netherlands Environmental Assessment Agency (MNP) and the National Aerospace Laboratory (NLR) about the noise measurement systems. The two renowned research institutes seemed not to agree upon the validity of the new calculation methods for determining the new limits for the noise enforcement points, while using the same dataset. Both responsible Ministers underlined that the noise measurement system of Schiphol was so complicated that almost no-one in the Netherlands actually understood it. This led to unnecessary mistrust. So in February 2008, the Dutch Parliament stated that they were fed up with these quarrels and complicated noise systematics with its enforcement points around Schiphol Therefore, the Alders Table was asked to design a new noise measurement system - one that was understandable, less technical, enforceable and transparent; also for laymen.

So, the discussion concerning the final advice of the Alders Table culminated in two major negotiating points: the total amount of air transport movements in 2020 (still not decided upon from controversie 2); and a new noise measurement system with or without noise enforcement points and understandable for politicians and laymen. Eventually the solution was a matter of give and take; the aviation parties would accept a final restricting capacity at Schiphol concerning total air transport movements, if they would get their new noise measurement system without enforcement points. The inhabitants got their maximum capacity of air transport movements at Schiphol with a $2+1$ operational strategy, and the aviation sector got a new safety measurement system, which was accepted by the other parties. Only the role of the BRS became very marginal in this sense, while they couldn't decide for one of these options.

\section{Controversy 4: Final advice}

And so, on 1 October 2008, Hans Alders presented his final advice concerning the future developments of Schiphol in reference to the regional capacity and absorption capacity. The final advice offered a maximum capacity of (480.000 air transport movements in 2010) and 510.000 
air transport movements until 2020, recommendations concerning selectivity with regard to socalled hub aviation operations and others, the development of regional airports for the non-hub operations, the introduction of a new noise-measurement system without enforcement points, the implementation of nuisance-reducing measurements, the implementation of Continuous Descent Approaches and investments in projects to improve the quality of the direct surroundings. It was presented as a historical advice, although the advice still consisted of several open ends, which proved hard to fill-in. For instance, so far only 7 of the 20 noise hindrance reducing measures have been (partly) implemented. Some will never be implemented as they were cancelled because of financial or operational difficulties. Moreover it is still not clear if Schiphol would be able to restrict itself to 510.000 air transport movements in 2020, while it si still not sure if (non-hub) flights can be relocated towards the regional airports. As such the discussions concerning hub-selectivity on Schiphol is still far from completed.

Furthermore investments in projects to improve the quality of the direct surroundings were met with lot of criticism and it is not sure at all that a planned second tranche of projects will ever commence. And finally, Continuous Descent Approaches (CDA)- although it was a very important cornerstone of the advice for inhabitants (because it could lead to a serious amount of noise hindrance reduction) - should have been implemented during the evening hours in 2010 already, but this is still not the case. As such the final Alders advice included in fact already the latent controversies for the near future.

Somewhere here Figure 1: Timeline Alders Table

\section{Discussion}

So, to what extent was the Alders Table a success? Was the deliberative body able to tap into the diversity of the complex governance system, creating windows of opportunities for mutually reinforced change? At first sight it seemed to do so. Alders understood the complexity of the airport governance system and developed the deliberative body around the most important subjects and actors. Moreover the authority of the Alders Table within its complex governance surroundings made it able to enforce self-organising associations. Finally by allowing mutual readjustments the Alders table resulted in a productive dynamic and could come up with a seemingly impressive package of proposals for reform. As such Van Buuren et al. seem to have rightly claimed the success story of the Alders Table. But researching this claim more profoundly, with help of the ANT-tools shortly noted before, we have reason to doubt a positive answer. 
First, rather than focussing on the highly embedded realms of the Alders table, one could also regard this consultative body as an excuse for the national government to get rid of the intricate, head-ached Schiphol portfolio. As the Minister was now able to inform the Parliament that the Alders advice was in line with the ambitions and wishes of all the Schiphol stakeholders leaving less or even no room for discussion: 'the people have spoken, who are we as representatives of the people to question their conclusions?' Nevertheless, concerned actors endorsed in our interviews that formulating the Alders advice was primarily a Machiavellian exercise (De Jong 2012). Hans Alders aimed for an advice signed by all parties, which he could present to the Minister. It was not important how the advice was formulated as long as all parties could live with it. Moreover the Alders Table did not present a widely supported advice, but became an advice, frustrating people along the way. As we have shown in controversy 4, the final Alders advice contained numerous unrealistic, non-imaginable and even contested proposals. Therefore, much of the advice was not carried out and created already new (potential) deadlocks and controversies between the various stakeholders. The Alders Table did not reduce or resolved the complexity of the governance system around Schiphol, but rather postponed it, perhaps even condensed and deepened it again into larger, newer and sharper controversies.

So in order to overcome deadlocks in complex decision making processes and to improve the impact of collaborative problem solving with regard to for instance major Hub Airports, do we really need to focus on a better intertwinement of collaborative governance attempts with other parts of the governance system? The argument presented here, in the case of the Alders Table, doesn't support the firm positive conclusion by Van Buuren et al., or at least claims that it is only part of the solution and perhaps even a minor one. Instead of linking al the interests together, intertwining the various subsystems towards a comprehensive agenda, our analysis sooner points at downscaling the comprehensiveness to concrete, specific agenda's one can handle and oversee. Only in this way, one could bend all the needed or involved human and non-human actors around it. Not complicating the problem towards more complexity (just hoping that this would bring new solutions), but operationalizing complex problems by clearing the disposition of its complexity, looking for new associative opportunities with interested partners on very clear and specific items and mutual agreements on 'what's in it for me'. It would need a more precise, instead of a more comprehensive actor-relational-approach.

Secondly, subsystems and governance systems should not be looked upon as containers - or a given context in which other actants act - but also as actants, reciprocally and dynamically influencing others as well as themselves. Helping such a kind of co-evolutionary process needs more and better resilient associations. It would be a major task for planners and politicians, 
without knowing before hand how this would develop or end. As said before, it would need a refocus on 'policies in the making' instead of 'ready made politics'.

Last but not least, it would mean going beyond the plan or intended political goals or agenda's. Beside the fact that those plans and those agenda's would be hardly realistic in the present fragmented, complex, highly volatile, non-linear and unpredictable networked world, these plans and agenda's would also restrict the intended co-evolutionary processes within its predefined pathdependencies, only resulting into repressive lock-ins. Perhaps noise annoyance measures ex ante, instead of hindrance reducing measures afterwards (De Jong 2012), more precise actor-relational mitigation strategies based on collaborative user maximization principles (Boelens 2009) or setting the scene for planning as an empty signifier within hybrid forums, instead of master signifiers such as globalization, sustainability and multifunctionality (Gunder \& Hillier 2009) would a better way to proceed. But all these tactics or strategies wouldn't so much need a better intertwined of complex governance decisions, with other parts of the systems, but sooner more precise (formal and informal) institutional settings, each in their own right.

\section{Conclusion}

In their contribution to Systems Research and Behavioral Science Van Buuren et al. put collaborative arrangements within the complex system characteristics of the respective governance system on the agenda in a renewed way. They argue that the Alders Table, as a collaborative problem solving effort at the Airport Schiphol, would be a successful example in this respect. However, looking at the proceedings within the Alders Table more proactively as 'policy in the making', instead of retrospectively 'ready made politics', we come up with another conclusion. With help of the Actor Network Theory, we can show how socio-technical controversies and normative and cognitive disagreements lead to the deployment of immutable mobiles and processes of translation. Through stratification of materials and mobilization of allies, closure is pursued. However, this closure proves to be very fragile. While although the Alders Table became an advice, it failed to become a resilient association. In ANT-terms the Alders Table didn't so much function as a mediator (a platform that organize the associations or networks) but as an intermediary (the facilitator which is also part of and organized within networks). In fact that is mostly the case with regard to consultative bodies and planning and complex decision making in general. Nevertheless, as with every new controversy, groups are being made and remade, spokespersons are being questioned, and associations are being rearranged. As such, the Alders Table advice was already out-dated when it was presented to the minister and parliament. 
When present governmental actions are not able to cope with these dynamic, non-linear developments, the question remains how planners and policy makers should react to sociotechnical controversies, and therefore to a resilient decision-making process concerning the future of Amsterdam Airport Schiphol, other major airport hubs or even complex challenges in general. Not Van Buurens at al. embeddedness, but precisely these items are usually neglected by studies regarding collaborative arrangements and complex governance systems. It gives the ANT research framework its added value. Therefore in order to overcome those deadlocks, planners and policy makers should restrain the fixation on scientific knowledge and focus on shared uncertainties instead. In order to improve decision-making in complex situations we need to refocus on more precise policies in the making, open and dynamic, without predefined goals or ambitions, instead of collaborative arrangements with ready made politics in related governance systems. 


\section{References}

Boelens L. 2009. The Urban Connection An actor-relational approach to urban planning. Rotterdam: 010 Publishers.

Boelens L, Jong B de. 2006. Constellatie Schiphol - De nationale luchthaven op de overgang van (semi)overhead naar doorslaggevende actor in de netwerksamenleving, in: Planning zonder overhead een toekomst voor planning, Boelens L, Wissink B, Spit T. (eds.). Rotterdam: 010-Publishers: 85-114

Buuren A, Boons F van, Teisman G. 2012. Collaborative Problem Solving in a Complex Governance System: Amsterdam Airport Schiphol and the Challenge to Break Path Dependency. Systems Research and Behavioral Science 29: 116-130.

Callon, M. 1986. Some elements of a sociology of translation: domestication of the scallops and the fishermen of St Brieuc Bay, in: J. Law (ed) Power, Action and Belief, a new sociology of knowledge?: 196223. London: Routledge and Kegan Paul

Callon M, Latour B. 1981. Unscrewing the big Leviathan: how actors macro-structure reality and how sociologists help them to do so, in: Advances in social theory and methodology: towards an integration of micro- and macro-sociologies, Knorr-Cetina K, Cicourel A. (eds.). London: Routledge and Kegan Paul: 277303

Farías I. 2011. Introduction: decentring the object of urban studies in: Urban Assemblages: how actornetwork theory changes urban studies, Farías I, Bender T. (eds.). London: Routledge: 1-25.

Hisschemöller M, Hoppe R. 2001. Coping with Intractable Controversies: The Case for Problem Structuring in Policy Design and Analysis, in: Knowledge, Power, and Participation in Environmental Policy Analysis, Hisschemöller M, Hoppe R, Dunn WN, Ravetz JR. (eds.). Transaction Publishers, New Brunswick and London, 47-72 .

Hommels A. 2011. Changing obdurate urban objects: the attempts to reconstruct the highway through Maastricht, in: Urban Assemblages: how actor-network theory changes urban studies, Farías I, Bender T (eds.). London: Routledge: 139-161.

Jong B de. 2012, forthcoming. The Airport Assembled: Rethinking planning and policy making of Amsterdam Airport Schiphol by using the Actor-Network Theory.

Latour, B. 1986. The Powers of Association, in: Power, Action and Belief - A new sociology of knowledge? Sociological Review monograph 32. Law J (ed.). Londen: Routledge and Kegan Paul: 264-280 
Latour, B. 2004. Politics of Nature: How to Bring the Sciences into Democracy. Cambridge: Harvard University Press.

Latour, B. 2005. Reassembling the Social - an introduction to Actor-Network-Theory. Oxford: University Press.

Law J.1992. Notes on the theory of the actor-network: ordening, strategy, and heterogeneity. Systems Practice 4: 379-393

Mol, A. 2002. The Body Multiple: Ontology in Medical Practice. Duke University Press.

Teisman G, van Buuren A, Gerrits L. 2009. Managing Complex Governance Systems - Dynamics, SelfOrganization and Coevolution in Public Investments. Routledge: New York, London. 
Figure 1: Alders Table timeline

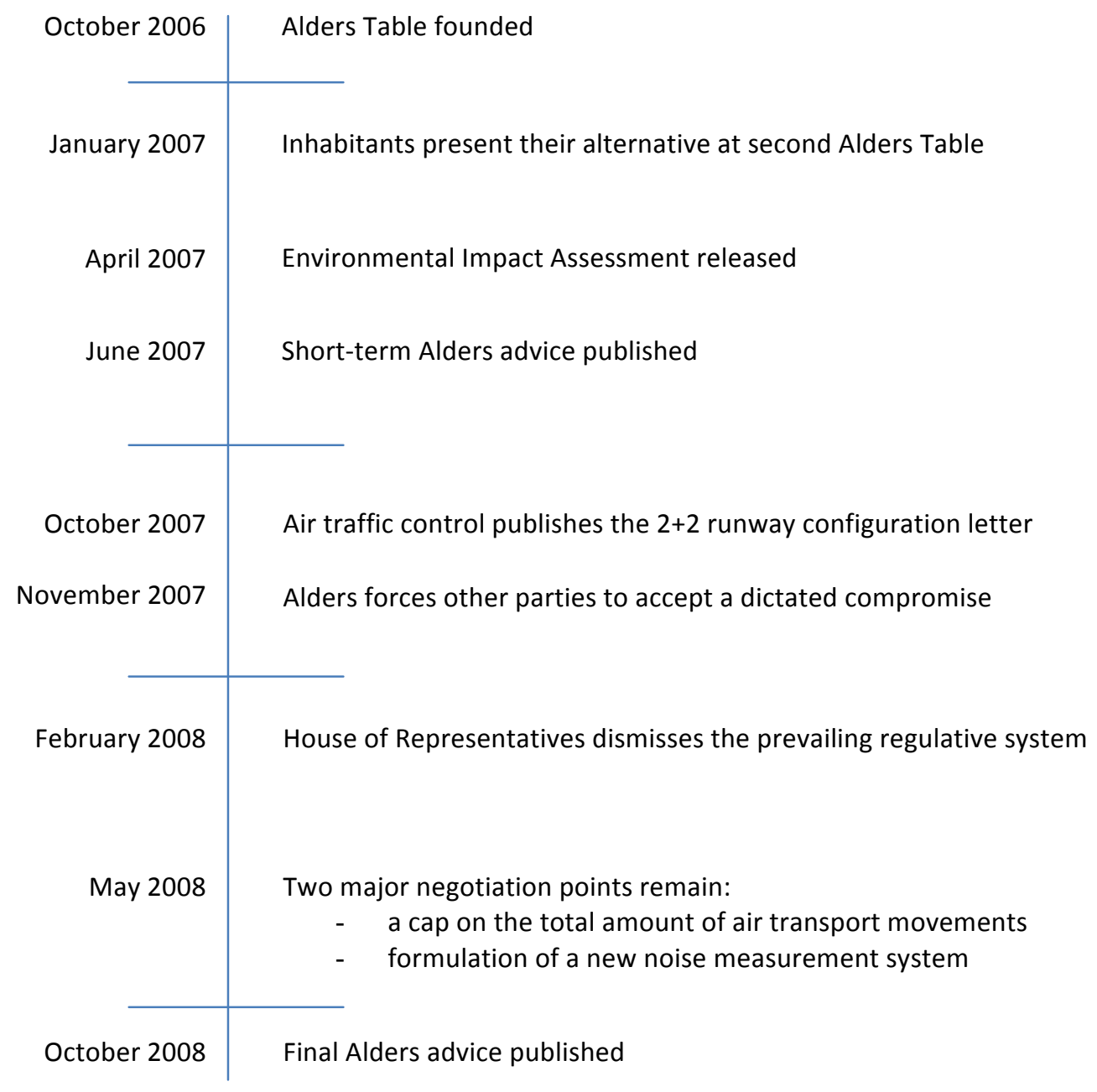

